\title{
Facilitating Learning With a Project-Based Curriculum That Engages 1st- Year Engineering Students
}

\section{Dr. Mike Elmore, Binghamton University}

Dr. Mike Elmore is director of and a visiting associate professor in the Engineering Design Division in the Watson School of Engineering and Applied Science at Binghamton University, State University of New York at Binghamton, NY. He holds a B.S. in Electrical Engineering from the University of Vermont in Burlington, VT, a M.S. in Electrical Engineering from Syracuse University in Syracuse, NY, and a Ph.D. degree in Electrical Engineering from Binghamton University. He has worked for Lockheed Martin, IBM, General Electric, BAE Systems, and Celestica Corporation. He has 25 years of experience in these companies designing military and commercial power electronic circuits and as a systems engineer for airborne and land vehicle electrical systems. He is a licensed professional engineer. He also received a B.A in philosophy and a M.Ed. from the University of Vermont. Before becoming an engineer he was a high school mathematics teacher.

\section{Prof. Sharon B Fellows, Binghamton University}

Assistant Director, Engineering Design Division, Freshman Engineering Program

\section{Mr. Koenraad E Gieskes, Binghamton University}

Koen Gieskes first joined the Engineering Design Division at Binghamton University as a graduate student in 2004, then, in 2009, he became a full-time lecturer. In this role, he serves as the engineering lab coordinator for the WTSN 111/112 courses. Mr. Gieskes received both his B.S. and M.S. degrees in Mechanical Engineering from Binghamton University and is currently pursuing his Ph.D. in Mechanical Engineering at Binghamton University.

\section{Mr. Lee A Cummings, Binghamton University}

Lee A. Cummings was appointed as the Subject Librarian for Engineering at Binghamton University in August of 2012. Prior to obtaining his Master's in Library and Information Science (M.L.I.S.) from Wayne State University, he obtained his B.S. in Industrial Engineering from the University of Toledo. His professional experience also includes work in project management, manufacturing, and supply chain operations. 


\section{An Innovative Approach to First-Year Design Projects: Facilitating Learning through a Project-Based Curriculum That Engages Students}

Abstract

At Binghamton University the State University of New York, Engineering Design Division faculty in the Watson School of Engineering and Applied Science have found that when facilitated student learning is the focus, students are engaged, resulting in motivation to succeed and increased retention rates. In the Engineering Communications classes of the first-year core courses, activities are created that generate inquiry through project-based learning. This approach has proven to enhance the classroom experience and retain first-year engineering students. Several approaches in the 2013 and 2014 spring semester design projects were taken: instruction in the development and writing of project requirements; an increase in team size; pairs within teams researching alternative designs; and a culminating exposition in the form of a competition. This paper describes a semester long first-year engineering conceptual design project that engages students in the design process in a way that allows them to experience being engineers and places the faculty member in the role of facilitator. A description of the design projects, the changes made in the spring 2014 semester based on the student and faculty feedback from spring 2013, and the results of data collected in the 2013 and 2014 spring semesters are reported.

Introduction

When student facilitated learning is the focus of a team project students must manage their own learning, if they are to succeed. In the Engineering Communications class, a two hour component of the required first-year core course, the semester long conceptual engineering design project is designed to generate inquiry through project-based learning. The structure of the first-year program includes a two hour per week Engineering Communications discussion section, a two hour per week Exploring Engineering lab, and a one hour lecture. The Engineering Communications classes and the Exploring Engineering labs are linked; the same twenty-four students are in each component. The lecture is attended by 288 first-year students. Fig. 1 illustrates the program structure.

The curriculum in the spring Engineering Communications course is designed to teach project and time management skills, as well as, build on team work skills learned in the fall semester. The focus of the spring semester is to build the critical thinking skills of students through writing, reading, and an understanding of the importance of reliable research, while learning the in-depth research process involved in solving an open ended engineering design problem. This focus challenges students to learn how to learn by engaging them in a project that requires students to seek information and methods to conduct the research needed to do the design. The research process is described later in the paper. Studies in engineering education show that students prefer courses that include application-based work and projects where problem-solving skills, design skills, and creativity can be applied ${ }^{1}$.

Baillie and Fitzgerald ${ }^{2}$ found that students who dropped out of engineering programs did so because the classes were not challenging and were uninteresting. Creating projects where 


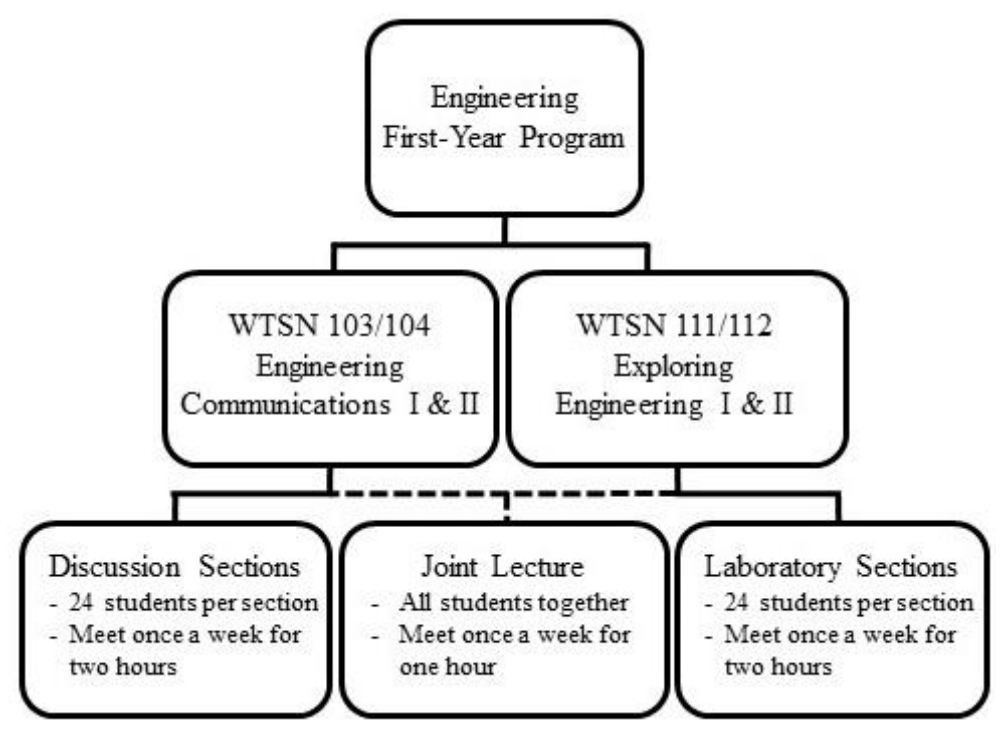

Fig. 1. First-Year Engineering Course Structure

students work collaboratively on student driven, inquiry based problems, and creating a classroom format that puts instructors into the role of facilitators of knowledge in the learning process has transformed the classroom into a challenging and more interesting environment. The Engineering Communications discussion sections are studies in controlled chaos. Weekly, three teams of eight members each (the same teams are in the linked engineering labs) are actively engaged in different levels of project work. The teams arrange the classroom so that the eight team members can more easily talk and share work. Computers are opened. White and black boards are used, as team members demonstrate concepts and ideas to each other. In some areas large sheets of paper are taped to the walls for this same purpose. It is usually noisy. The instructor is somewhere in the room either working with teams, pairs, or individuals. Two undergraduate course assistants are managing the routine administrative classroom minutia that would normally prevent the instructor from being free to move throughout the classroom assisting teams as needed.

Though it is noisy and the sound of laughter can be heard from time to time, if one were to observe closely, it is clear that work on the projects is being accomplished and every student is engaged. Students are free to approach tasks in their own way. One team brought in newspapers to make hats to wear while they were brainstorming approaches to their design project. When asked about the hats, they said the hats broke down any inhibitions they had about feeling that their ideas might be silly and provided the impetus to "go outside the box." The new eight team member format, as opposed to the four person team format in the fall, does not allow any student to hide from their responsibility to the team. In other words, all students are held accountable for their fair share of the project work. For the most part, students are enjoying the experience, while learning to manage their own learning.

This study uses survey data and an analysis of retention over a five year period to assess the effectiveness of the several approaches used in this project-based curriculum to more fully engage first-year students. 
Project Descriptions

The projects in spring 2013 were selected by the engineering Graduate Teaching Assistants (GTAs), who work within the first-year program. Each GTA represents one of the engineering disciplines within the Watson School: Mechanical, Electrical, Computer, Systems Science and Industrial, and Biomedical engineering departments. Each GTA submitted three ideas and presented them to the Engineering Design Division faculty, who made the final decisions. The engineering faculty then wrote a brief summary of each project for the students. Each GTA serves as an imagined Chief Executive Officer (CEO) for their particular project. The GTA makes the final decisions about the project requirements that students write and manages an electronic site for project questions and answers to assure that consistent information is communicated to each team. Each electronic site includes a more detailed description that might include specific constraints. There are 288 students in the Engineering Design Division first-year program; thirty-six teams of eight students. The projects and number of teams per project for the spring 2014 semester follow:

1. Design a visually appealing and attractive Campus Dining Hall that would be cost effective while allowing students to get their food and pay for it without standing in line for a lengthy period of time. (6 teams)

2. Develop a mechanism that would vary the position of horizontal axis wind turbines to maximize electrical output in any wind conditions. (4 teams)

3. Design a system that controls access to the Binghamton University Bike Share bikes. (1 team)

4. Design a prosthetic hand using a combination of 3D printer and hobbyist single board microcontroller technologies that results in a more dexterous hand than the whole-hand-grasp mechanism. (8 teams)

5. Design a system that generates usable electrical power from the doors in a specific building on campus. (10 teams)

6. Design a wearable power system for personal electronic. (7 teams)

\section{The Engineering Conceptual Design Project Overview}

The key steps in the project are illustrated in Fig. 2. During the first class of the semester individual students read and select the projects on which they wish to work. By ranking their choices they end up on a team that is one of their top three choices. This important first step assures a student's interest in the project to which they are assigned. The engineering conceptual design project requires that all team members complete each assignment in order to understand the issues surrounding the design the team will create. Each team member's contribution is unique to the successful completion of the project. A team task schedule, similar to a Gantt chart, is developed by the team to consider every project task through the culminating public exposition.

Students are asked to read several kinds of texts and conduct research to understand the project in more depth. After team members have researched sufficient information about the 


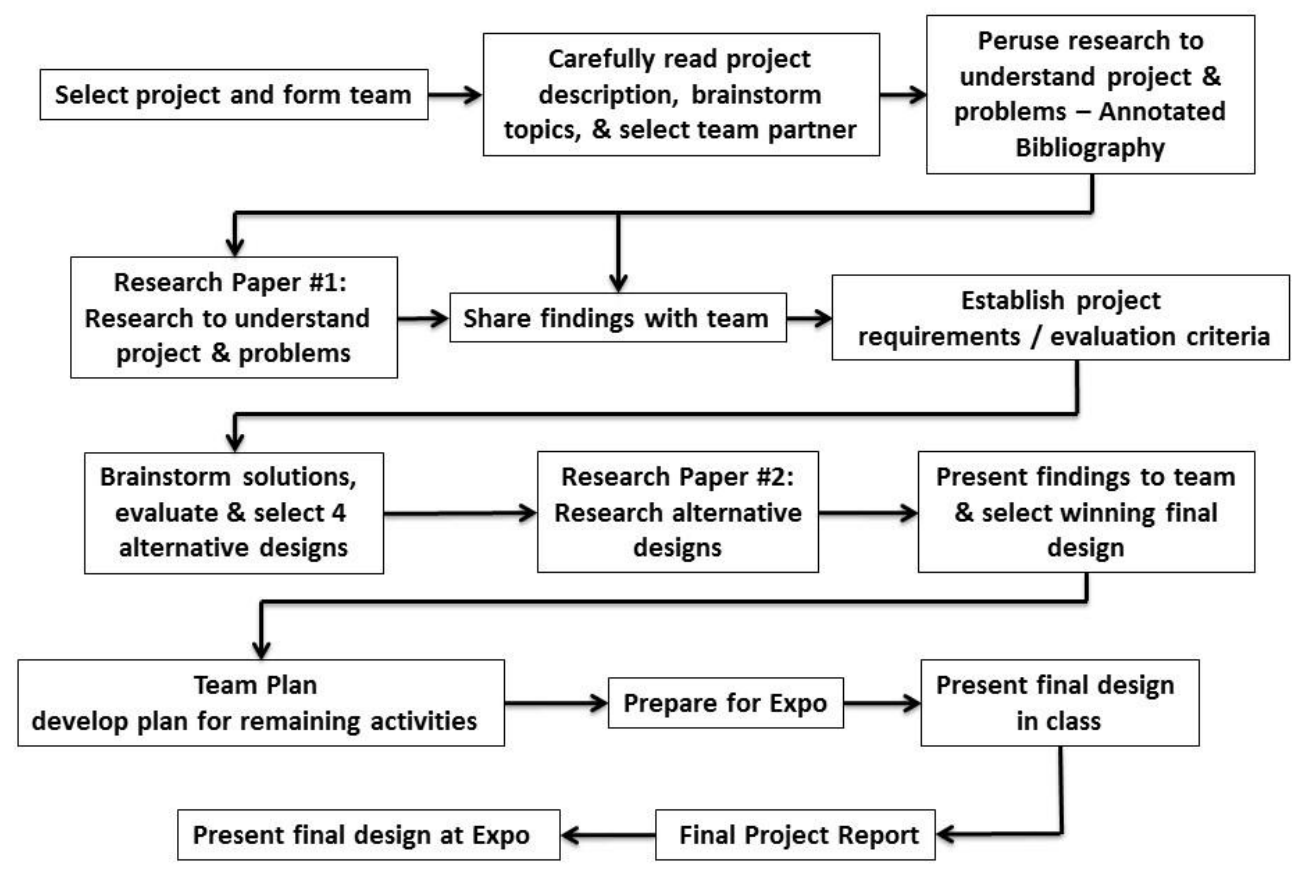

Fig. 2. Project Flow Chart Key Steps

project they summarize their findings in the first research paper. Guided by the brief project summary and their research, the students now write about 20 detailed design requirements that must be met by their final design. Similar requirements are grouped within a system structure (i.e., electrical, logistical, safety, etc.). These groupings are used as evaluation criteria for selecting between alternative design approaches. The requirements and evaluation criteria are approved by the CEO. A more detailed discussion of the design requirements process follows later.

Next, the team brainstorms and evaluates potential alternative designs for the project. The teams of eight narrow down the potential designs to just four alternative designs. At this point team members select the alternative design they are most interested in developing further. This process is complete when four pairs of students are formed with each pair working on one of the alternative designs. The pairs schedule out of class meeting times to develop their alternative designs. While developing their alternative design, each pair of students determines what research is needed to complete the design. This research becomes the basis for the next research paper.

Upon completion of the alternative designs, each pair develops a PowerPoint presentation with provided guidelines to present to the full eight student team showing the details of the design. Then, during one class period each team of eight views all four presentations and the alternative designs are ranked using the Pahl and Beitz criteria matrix. This process determines the winning solution. The team has the option of combining solutions by adopting the best parts of each alternative design. The pairs then come back to their eight person team to work on the one final design for the project. They can use some of the better parts of the rejected alternative 
designs, if appropriate for the final design. The final design must meet all of the design requirements. The design is documented through a series of assignments, a final report (introduced in spring 2014), and a model of the design. The model can be either a computer model, a physical prototype, or both.

The Exposition is in the form of a professional poster presentation held the last week of classes in which teams demonstrate the final design and what the team has learned. Each project is evaluated by a team of judges comprised of faculty members from within the Watson School, engineers from local industry, and other professional staff or University personnel.

\section{Class Format, Team Size, and Facilitated Teaching}

The decision to create teams of eight was made to better simulate the experience students would have in their senior design capstone project. In discussion with industry leaders, the larger team better simulates what students will experience in industry. However, from the first week of classes, once teams were formed, students were instructed to find a partner within the team with whom to work on assignments. This provided a support system for students as the research intensive process began. In a survey students commented that group studying had a positive impact on understanding the material and was carried over into other classes as well. Honken and Ralston in their recommendations to improve retention in engineering programs found "since students who studied together in high school more frequently were more likely to continue in engineering, opportunities for students to develop the habit of studying with others should be provided."3

An unexpected outcome of creating the larger teams was the observed involvement of all students in the project. The spring 2013 semester was the first experience with the larger teams. Course instructors noticed the increase in individual student involvement. Speculation about the success of this change varied. The course format changed from having weekly meetings outside of class for teams of four in the fall, to using the two hour Engineering Communications class time as an in-class team meeting with the first half hour to forty minutes used to provide instruction. When surveyed, student responses were positive, since they now did not have to manage the difficult scheduling involved in out-of-class team meetings, especially for a team of eight. When situations within specific teams arose that required a team to meet outside of class, they found a way to coordinate schedules and meet. Leaving the decision to the teams to work out difficulties in their own way worked. It must be noted that all students were involved in weekly team work instruction in the fall semester in the areas of communication, leadership, trust, decision making and conflict management. Instructors agree that the lessons learned in the fall were carried over into the spring, resulting in less team conflict. It was also noted that the larger teams made it more difficult for individuals to "hide" or not participate, because there were more students to "call them out" for not doing the required tasks. Several comments from students were along the lines of, "... it is not very comfortable to look bad in front of seven other team members." The practice of forming pairs to work together within the larger team also required individuals to perform better in an effort "to not let their partners down." Later in the semester, each team's members were required to report weekly on the progress of the work completed on the team task list and to show the work they had individually accomplished. 
Though Blackboard is used as the main course organizational tool and text site, a course pack was developed for the Engineering Communications course that is organized by weeks. It includes materials needed in class and guidelines for homework. The in-class material includes a team task list of items that must be completed during class time, much like lab work. Teams make decisions about how the in-class project facilitation is managed. The student facilitator leads the team through the task list.

In spring 2013 some teams chose a student facilitator to serve for several weeks, while other teams rotated the responsibility weekly. Teams decided on other roles team members would perform to complete the tasks. Teams became creative in the roles that were assigned. Often there were two or three "googlers" who would quickly look up information that was not known, but needed during team discussions about the projects. Time keepers were assigned to monitor the progress of each task to ensure the team finished within the class time allotted for work that day. Note takers were assigned to record minutes and "sketchers" drew pictures and diagrams to stimulate discussion and provide another perspective. It was clear that when students were given control of their learning, they would go beyond what might have just been assigned by the instructor.

The teacher as facilitator approach was a new experience for most students. The instructor rarely provided a definitive answer to a student's questions about team process, but instead instructed teams to discuss issues and make decisions. As discussed in the previous paragraph, this approach was intended to facilitate independent thinking and in most cases the students demonstrated they could perform the tasks independently and creatively. The critical thinking skills needed by students to perform in this format were fostered and observed weekly in class by the instructors. Much of the class time was spent closely observing the team dynamics. Students analyzed design problems, organized ideas, and developed data representations of their decisions. As the semester progressed, teams were choosing materials, debating with teammates, deciding on a course of action, evaluating designs, and assessing failures. Student creativity increased when teams began generating new ideas, designing solutions, hypothesizing what would happen, and constructing and redesigning models. For many students, this approach was the first time they were put in a learning situation where the answers were not in the book or given by the teacher. Students' confidence in their ability to be successful grew as the decisions they made and the knowledge gained from the research led them toward a design for their project. Instructor intervention to assist teams was minimal, compared to previous years.

\section{Research}

Developing good research habits and information retrieval skills was an important component of the coursework and the importance of this lifelong skill was stressed early in the semester. A close collaboration with the subject librarian for engineering, as well as, other library staff was established several years ago. It has evolved to the level of including the engineering librarian as part of the instructional team with access to the main Blackboard site as a course builder. This connection allows the posting of new materials in the literature throughout the semester. 
The research requirement was established from the beginning of the course, as annotated bibliographies from initial research were due in the second week of the semester. Completion of the first research paper followed in the third week. For students to begin their project an initial understanding of the topic was required. The link between the project content and the research process was established early. It quickly became clear to students that finding reliable sources, and synthesizing their findings into a coherent document was crucial to the success of the project. As ABET's current criteria for accrediting engineering programs states, an important outcome of engineering education is recognition of the need for, and the ability to engage in lifelong learning ${ }^{4}$. To engage in life-long learning, engineers need to be information literate. According to the Association of College and Research Libraries, this allows them to recognize when information is needed and gives them the ability to locate, evaluate, and effectively use that information ${ }^{5}$. To increase students' information literacy, Binghamton University Libraries provided research help, instruction, and support for the course in a number of ways.

The subject librarian for engineering visited each of the thirteen Engineering Communications course sections in the second week of the semester to inform students of library services. Library resources developed specifically for students - namely, an online subject guide for the course that compiled a selection of texts, journals, and databases that were highly relevant for the projects being undertaken. The subject guide was organized with the input of course instructors. In addition to research materials, the subject guide included important information on academic honesty and plagiarism, links to free internet sources, and recommended instructional materials from the library. Recommendations for new texts, including print and electronic books, were also submitted by the subject librarian to the instructors for consideration before purchase. And the library placed select print titles on reserve as needed. Students expressed positive comments throughout the semester about the engineering librarian and the on-line subject guide, especially as it was developed "just for" their course.

It has been stated that librarians serve as instruction partners in the education of engineers ${ }^{6}$, and such was the case during this course. In addition to selecting and organizing resources, the subject librarian provided small group and one-on-one instruction to students. Students new to the research process learned how to select and use electronic databases based on their research topics, how to identify the most relevant articles, texts, and web sources for their research, and how to go about accessing resources not readily available by utilizing interlibrary loan. These skills were critical throughout the semester, as students were required to regularly report on their research, and proposed designs, within the context of existing literature.

\section{Requirements Engineering}

Early in the semester, in the required weekly Exploring Engineering lecture, students were introduced to requirements engineering. This included an introduction to the types and characteristics of requirements. Students were provided with a detailed description and an example of how to develop and write requirements for their project solution. Along with two lectures on requirements engineering, these concepts were further discussed early in the weekly laboratory. The student teams were tasked with the generation of questions that would need to be addressed before a full set of requirements could be generated. These questions were then sorted into two categories. The first were questions that would need to be put to the CEO of their 
project to clarify what was expected. The questions of this sort were posted on the project forum along with the replies and were visible to all students working on that project. The second type of questions was those that would require more research to be done by the students in order to find an answer. In the example, which was a design to provide potable water for a village, the students might have a question like, "How much water is consumed by an individual per day?" Before their next Engineering Communications section, the students were tasked with finding the answers to these types of questions. Once the questions were addressed, the student teams developed the first draft of their project requirements. They took a hierarchical approach to writing the requirements that emphasized a systems point-of-view. The potable water for a village design that was proved as an example is shown in Fig. 3. These higher level categorizations became the evaluation criteria for the Pahl \& Beitz evaluations of alternative designs. Then detailed requirements were written for each higher level categorization. A sample requirement is shown in Fig. 4. Once the team had written the first draft of all requirements for the project, they sent the requirements to the CEO of their project who accepted them, rejected

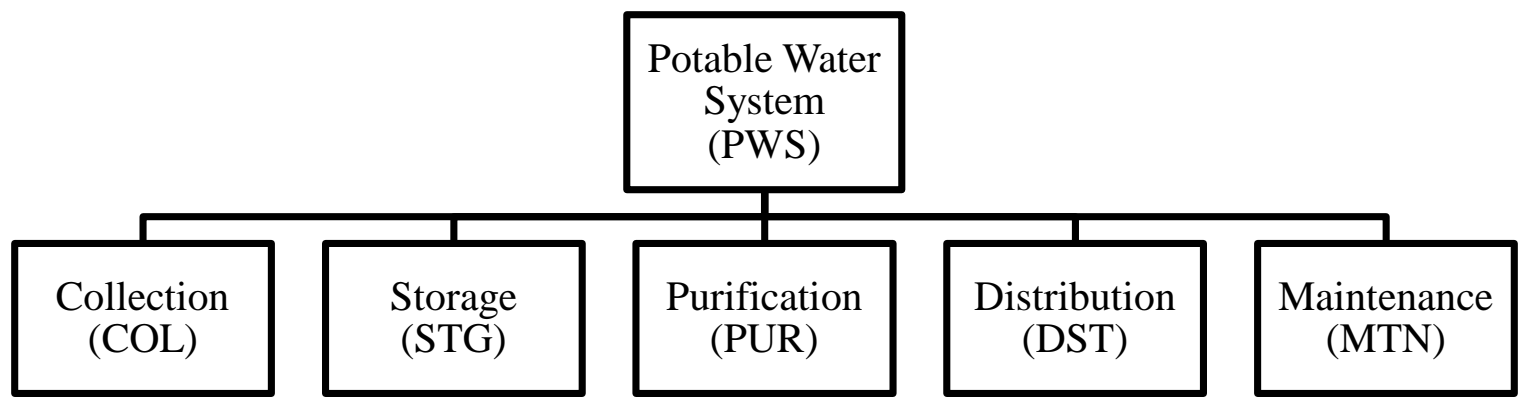

Fig. 3. System Structure and Evaluation Criteria

them, or suggested changes. The TA, functioning as the CEO responded to the teams within the same week. Once the final design had been completed, the teams had to verify that the design met each requirement. This was done by analysis. The analysis could be in the form of a simulation, mathematical derivation, or logical argument. If a prototype were actually built, then a demonstration or inspection could be done.

Some teams and individual students struggled with developing and writing requirements. In a survey students indicated that in the end the solution they developed was stronger than it would have been without going through the process of understanding the importance of requirements

System

Component

Level

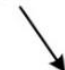

[COL 2.1] An empty PWS shall be refilled in no more than 6 hours. [PWS 1.1 \& PWS 1.3\}
Parent

Requirement(s)

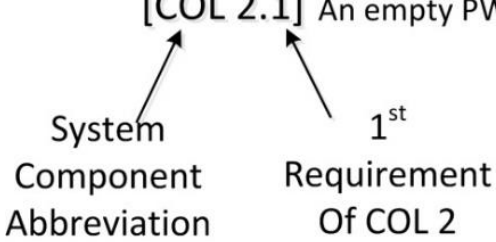

Fig. 4. Format for Requirements 
and verification. A frequently asked question concerned the relevance and application of this method in engineering within the work place. Because developing, writing, and verifying requirements is used in senior design, this first introduction to the process offers a glimpse into their future.

Results

Table 1 summarizes first-year engineering student retention in the Watson School over a five year period. WTSN 103/111 (fall) gives the number of students enrolled in WTSN 103 and WTSN 111 about one week into the fall semester. WTSN 104/112 (spring) gives the number of students enrolled in WTSN 104 and WTSN 112 about one week into the spring semester.

Declarations are the number of students who declare a major in one of the engineering departments in the Watson School in April of the spring semester. Over the five year span of data it is noted that Fall-to-Spring Retention (\%) has averaged $90.8 \%$ with a range of $89.9 \%$ to $91.9 \%$. On the other hand the retention from Spring-to-Declaration retention $(\%)$ has averaged $94.5 \%$ with a range of $90.1 \%$ to $97.9 \%$. Clearly fewer students, as a percentage, are choosing to remain in engineering after the fall semester than the spring semester.

A closer look at Spring-to-Declaration Retention (\%) shows that in the three years prior to the introduction of the project-based curriculum described in this study, the spring 2013 semester retention has averaged $92.6 \%$ with a range of $90.1 \%$ to $94.1 \%$. Whereas in the two years the project-based curriculum has been in place the average Spring-to-Declaration Retention (\%) has averaged $97.4 \%$ with a range of $96.8 \%$ to $97.9 \%$. While causality cannot be proven here, there does appear to be a correlation between the introduction of the project-based curriculum and increased retention.

Other changes were made to the course structures of WTSN 103/111 and WTSN 104/112 during the 2012-13 and 2013-14 academic years that might at first thought account for the

Table 1 - First-Year Retention

\begin{tabular}{|c|c|c|c|c|c|}
\hline & $\mathbf{2 0 0 9 - 1 0}$ & $\mathbf{2 0 1 0 - 1 1}$ & $\mathbf{2 0 1 1 - 1 2}$ & $\mathbf{2 0 1 2 - 1 3}$ & $\mathbf{2 0 1 3 - 1 4}$ \\
\hline WTSN 103/111 (fall) & 267 & 321 & 317 & 383 & 307 \\
\hline WTSN 104/112 (spring) & 240 & 293 & 287 & 347 & 282 \\
\hline Declarations & 225 & 264 & 270 & 336 & 276 \\
\hline $\begin{array}{c}\text { Fall-to-Spring } \\
\text { Retention (\%) }\end{array}$ & 89.9 & 91.3 & 90.5 & 90.6 & 91.9 \\
\hline $\begin{array}{c}\text { Spring-to-Declaration } \\
\text { Retention (\%) }\end{array}$ & 93.8 & 90.1 & 94.1 & 96.8 & 97.9 \\
\hline $\begin{array}{c}\text { Fall-to-Declaration } \\
\text { Retention (\%) }\end{array}$ & 84.3 & 82.2 & 85.2 & 87.7 & 89.9 \\
\hline
\end{tabular}


improved retention. During the 2013-14 academic year WTSN 111 and WTSN 112 lengthened the laboratory from 1-1/2 hours per week to 2 hours and went to a single 1-hour lecture per week from the previous two 1-hour lectures per week. However, improved retention had already been seen in the 2012-13 academic year, the year previous to the introduction of the new projects

Also, in the 2012-13 academic year the class sizes in WTSN 103 and WTSN 104 were reduced from 32 students per section to 24 students per section. And as previously noted, the same 24 students in an WTSN 103 section were together in the WTSN 111 laboratory. WTSN 104 and the WTSN 112 laboratory were similarly linked. However, once again the improved retention was observed the previous academic year, before these changes had been made. Finally, it should be noted that there were no other significant changes to topics in WTSN 103, WTSN 111, or WTSN 112 or the manner in which the topics were presented, other than the introduction of the two systems engineering lectures in WTSN 112. The only change was to introduce the project-based curriculum in WTSN 104 with the larger teams and systems engineering approach to design.

Students were asked 5 questions in a survey that was administered on Blackboard near the end of the semester. The questions were:

1. What did you like about the spring project?

2. In comparison to the two fall projects and the team size, please comment on the effectiveness of the larger teams and the use of pairs.

3. What, if anything, would you change about the spring project?

4. What are other project topics you would recommend?

5. How helpful was it to develop the list of your requirements?

The answers to question 5 were categorized into 1) Helpful; 2) Somewhat Helpful; and 3) Not Helpful. The results are given in Table 2, along with a few representative answers. The authors find it satisfying that some of the students who felt that writing requirements was not that helpful, nevertheless, appeared to understand that requirements serve an important purpose. When students realize that "requirements limited us too much when deciding the final design", they have learned an important lesson about requirements and their role in design.

Many students answered question 2 in a manner similar to this student: "At first I was apprehensive, because I thought too many people will cause a wreckage during team meetings. However I absolutely love my team. We worked so well together. I really liked the concept of working individually researching a topic, then working with a partner on a possible final solution and then collectively as a UNIT working on one solution. Definitely continue that." Not all students liked the larger teams, but admitted to knowing that they would be part of larger teams in industry.

Conclusions

Many engineering students make important decisions during their first year that affect their educational career. The decision to reject engineering is often based on the complexity of the curriculum and the lack of engagement ${ }^{3}$. Based on the research and current experience it is clear 
that the need for change exists, especially in the first year, which is the corner stone of any academic program. Implementing innovative approaches to first-year design projects, can be time consuming and risky, but necessary to address the fundamental paradigm shift in engineering education. It requires that both students and teachers acquire pedagogical skills that are not always comfortable or do not fit the traditional approaches that the research shows do not work in the 21 st century.

Table 2 - Response to Question 5

\begin{tabular}{|c|c|c|}
\hline & Number & Example Comment \\
\hline \multirow{3}{*}{ Helpful } & \multirow{3}{*}{155} & $\begin{array}{l}\text { It was very helpful since developing the requirements gave us the } \\
\text { structure of what we needed to do. }\end{array}$ \\
\hline & & $\begin{array}{l}\text { Extremely helpful because it outlines exactly what must be done } \\
\text { and understood for the project to continue and develop. }\end{array}$ \\
\hline & & $\begin{array}{l}\text { It was pretty helpful and did lay down guidelines that were easy to } \\
\text { follow. The only problem we ran into was trying to verify all of the } \\
\text { requirements. We didn't realize the implications while making the } \\
\text { initial requirements. }\end{array}$ \\
\hline \multirow{3}{*}{$\begin{array}{l}\text { Somewhat } \\
\text { Helpful }\end{array}$} & \multirow{3}{*}{56} & $\begin{array}{l}\text { It was somewhat helpful. We already knew what we needed to } \\
\text { have but this allowed us to narrow down our project and be sure that } \\
\text { our final solution was on par with what an average user might need. }\end{array}$ \\
\hline & & $\begin{array}{l}\text { Developing a list of requirements did not so much help me } \\
\text { understand the problem as make me need to research the topic, which } \\
\text { helped me understand the problem. }\end{array}$ \\
\hline & & $\begin{array}{l}\text { The list of requirements wasn't that helpful in understanding the } \\
\text { project, but it made it easier to keep us on track with our project and } \\
\text { our design. I liked the requirements because they are needed in the } \\
\text { real world, and it made the project more realistic. }\end{array}$ \\
\hline \multirow{3}{*}{$\begin{array}{l}\text { Not } \\
\text { Helpful }\end{array}$} & \multirow{3}{*}{40} & $\begin{array}{l}\text { It was not good at all because we didn't know what we were actually } \\
\text { doing initially when writing them which made the requirements } \\
\text { extremely hard to deal with. }\end{array}$ \\
\hline & & $\begin{array}{l}\text { The requirements were not very useful and became somewhat } \\
\text { problematic towards the end of the project. As we began the project } \\
\text { we came up with requirements that sounded good but once the end of } \\
\text { the project came, we realized some of them were very challenging to } \\
\text { verify. }\end{array}$ \\
\hline & & $\begin{array}{l}\text { It wasn't very helpful at all, since we weren't entirely sure about the } \\
\text { specifics of our project, our requirements limited us too much when } \\
\text { deciding the final design. }\end{array}$ \\
\hline
\end{tabular}


For the first-year engineering program in the Watson School retention has improved. Anecdotal evidence from students and instructors suggests that the change in the first-year engineering program's approach plays a large part in keeping students engaged and wanting to further experience the world of engineering. The engineering design process was built into the curriculum in a way that allowed students to develop ideas, create designs, evaluate them, and communicate the results by thinking creatively and abstractly. Students developed effective communication skills by presenting their design plans, results, tests, and redesigns. They were able to articulate a particular approach to a design, what went wrong with a design, and what steps were taken to correct it. Students learned to document their design plans, design drawings, design changes, and verification results.

This paper describes a semester long first-year engineering conceptual design project that engages students in the design process in a way that allows them to experience being engineers and places the faculty member in the role of facilitator. The process to design the curriculum was time consuming, the faculty involved thought it was worth the effort. The results have proven to be successful. The course will continue to be improved and data collected.

\section{References}

[1] Bernold, L. (2007). Preparedness of Engineering Freshman to Inquiry-Based Learning. Journal of Professional Issues In Engineering Education \& Practice, 133(2), 99-106. doi:10.1061/(ASCE)1052-3928(2007)133:2(99).

[2] Bernold, L. E., Bingham, W. L., McDonald, P. H., \& Attia, T. M. (2000). Impact of holistic and learningoriented teaching on academic success. Journal of Engineering Education, 89(2), 191-199.

[3] Honken, N., \& Ralston, P. S. (2013). Freshman Engineering Retention: A Holistic Look. Journal of STEM Education: Innovations And Research, 14(2), 29-37.

[4] Accreditation Board for Engineering and Technology, "Criteria for accrediting engineering programs," 2014.

[5] Information literacy competency standards for higher education. http://www.ala.org/acrl/standards/ informationliteracycompetency.

[6] A. Naimpally, H. Ramachandran and C. Smith, Lifelong Learning for Engineers and Scientists in the Information Age. London: Waltham, MA: Elsevier, 2012. 